Abstracted/indexed in Academic Search Complete, Asia Journals Online, Bangladesh Journals Online, Biological Abstracts, BIOSIS Previews, CAB Abstracts, Current Abstracts, Directory of Open Access Journals, EMBASE/Excerpta Medica, Google Scholar, HINARI (WHO), International Pharmaceutical Abstracts, Open J-gate, Science Citation Index Expanded, SCOPUS and Social Sciences Citation Index;

\title{
A comparative study on the effects of niacin plus atorvastatin with that of fenofibrate plus atorvastatin in dyslipidemia patients
}

\author{
Salim Ahmed1, A. K. M. Mosharrof Hossain, Sudhangshu Ranjan Dey², \\ A. K. M. Akhtaruzzaman ${ }^{2}$, and Musammath Moriom Siddika3
}

Department of ${ }^{1}$ Pharmacology, ${ }^{2}$ Cardiology and ${ }^{3}$ Pediatrics, Sylhet M. A. G. Osmani Medical College, Sylhet 3100 , Bangladesh.

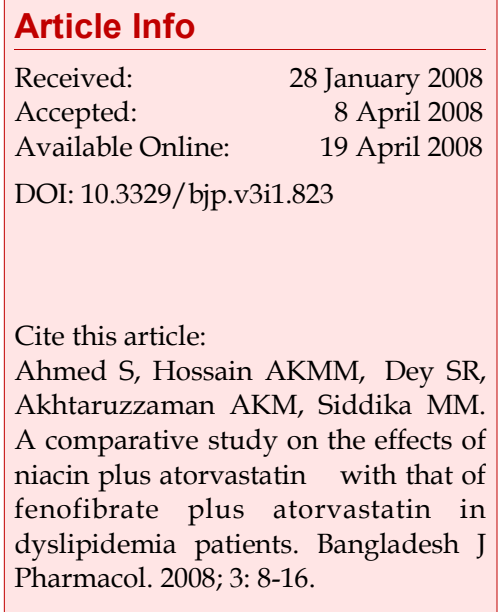

\begin{abstract}
The study was designed to evaluate and compare the effects of coadministration of atorvastatin $(10 \mathrm{mg})$ either with niacin $(1 \mathrm{~g})$ or fenofibrate (200 mg) daily for 12 weeks in 67 coronary heart disease patients with dyslipidemia. There were no significant differences among the two groups (35 patients in Group I and 32 patients in Group II) in serum lipid profile except in level of triglyceride reduction where fenofibrate-atorvastatin combination yielded significant $(p<0.001)$ results. SGPT level significantly raised and fasting blood glucose level decreased in fenofibrate-atorvastatin treated group than niacin-atorvastatin combination. Serum creatinine level decreased in niacin-atorvastatin treated group compared to fenofibrate-atorvastatin, but the changes was within normal limit. This study shows that both combinations are equally effective in dyslipidemia. Although, fenofibrate-atorvastatin combination decreased more triglyceride and niacin-atorvastatin combination appeared safer considering some adverse effects.
\end{abstract}

\section{Introduction}

Globally, cardiovascular disease contributes to one in three deaths (Eckardstien, 2005). Though cardiovascular disease death rates are declining in the developed countries (Chockalingam and Campbell, 2005) it becomes a leading cause of morbidity and mortality in the developing countries (Bovet et al., 2006). Every year, more than 15 million deaths occur in worldwide due to cardiovascular disease. Of them 9 million deaths are accounted for the developing countries (Chockalingam and Campbell, 2005).

The Americans and the South Asians exhibit the highest prevalence of coronary artery disease and coronary risk factors are more as compared with Caucasians (Deedwania and Singh, 2005). The coronary artery disease rates among Indians were 6 times higher than the Chinese and 4 times higher than the other Asian Americans (McKeigue et al., 1989).

In Bangladesh, cardiovascular diseases are becoming a significant burden on health care services (Sultana et al., 2002). Dyslipidemia plays an important role for provocation of cardiovascular disease (Miller, 2003). The major detrimental components of dyslipidemia are low high density lipoprotein cholesterol (HDL-C), high triglyceride and elevated low density lipoprotein cholesterol (LDL-C). Recent publications and guidelines have raised awareness of the need to prompt treatment of dyslipidemia to reduce cardiovascular risks in patients with diabetes or metabolic syndrome (Davidson, 2003). 
Low HDL-C is an independent risk factor for coronary artery disease and its prevalence is high and increasing (Gordon et al., 1977). The prevalence of low HDL-C appears to be high in Latin American subjects, as shown by surveys carried out in Mexico (92.1\% in men, $96.6 \%$ in women) and Brazil (50\% both men and women). In Mexico, the prevalence of low HDL-C increased by 2$3 \%$ within a period of only 7 years (Bruckert, 2006). The prevalence in UK showed that approximately one man in four and about one woman in twelve had low HDLC (Patel et al., 2004). The overall prevalence of low HDL -C was $33 \%$ in men and $40 \%$ in women. An elevated triglyceride often accompanies low HDL-C, found in 47 $-57 \%$ of men and $44-48 \%$ of women. Combined lipid abnormalities occurred together in $21-26 \%$ of men and $25-27 \%$ of women (Bruckert, 2006).

According to Framingham study, in older men and women from age 49 to 82 years, the most potent risk factor for coronary artery disease was low HDL-C. Low HDL-C had an inverse association with coronary artery disease in men and women. The association between LDL-C was weaker than HDL-C (Gorden et al., 1977). Low HDL-C together with elevated triglyceride is common dyslipidemia feature found in patients with coronary heart disease. In Veterans Affairs HDL intervention Trial (VA-HIT) on 8,500 coronary heart disease patients, $87 \%$ had elevated LDL-C levels, $64 \%$ also had low HDL-C levels and 33\% had elevated triglyceride level (Rubins et al., 1995).

Optimal dyslipidemia management, including therapeutic life style changes (TLC), is recommended for all patients at risk of coronary artery disease. However, TLC has limited effects on low HDL-C and therefore drugs are needed to help dyslipidemic patients to achieve lipid profile goals (Fodor et al., 2000).

At present available drug classes that modify lipid and lipoprotein metabolism are: Statin, bile acid sequestrants, fibrate derivatives, nicotinic acid and ezetimibe. The mechanism of action of statins, fibrates and nicotinic acid are distinct. The statin blocks the rate limiting step in cholesterol biosynthesis (Weirzbicki et al., 2003) and has the most powerful LDL-C lowering effects out of all lipid modifying agents (Deedwania and Singh, 2005). Niacin inhibits the release of free fatty acids from adipose tissue, increases lipoprotein lipase activity and decreases the hepatic production of VLDL$\mathrm{C}$ and LDL-C production. Fibrates belong to the drug classes that exert their effect by activating PPAR-a (Barter and Rye, 2006). Individually nicotinic acid and fibrates are the most effective pharmacological agents for dyslipidemia by raising HDL-C and reducing triglyceride (Grundy et al., 2004). Results of clinical trials with fibrates or nicotinic acid showed improve total lipid profile; strongly suggested a benefit (Barter and Rye, 2006).

The rationale for combination therapy is that drugs with complementary mechanism of action can provide complementary effects on the lipid profile (Venkataraman et al., 2004). The HDL Atherosclerosis Treatment Study (HATS) showed that combined effect of niacin or a fibrate with a statin improved HDL-C and LDL-C which inhibited the progression of atherosclerosis and reduced cardiovascular events in a high risk population with established coronary heart disease (Taylor, 2006).

Combination of statin-niacin therapy is associated with flushing and is usually transient but hepatic effects and myopathy are uncommon. The common adverse effects of statin-fibrate therapy are myopathy, elevated hepatic enzyme and gastrointestinal upset (Koh et al., 2005).

Previous studies established that statin in combination with fenofibrate significantly improved lipid profile than monotherapy in people with type 2 diabetes, dyslipidemia, and history of coronary artery disease (Derosa et al., 2004). Another combination therapy of statin-niacin, reduced LDL-C significantly more than niacin alone and HDL-C level significantly raised more than statin administration alone. It was also more effective in reducing triglyceride levels than either monotherapy (Misra et al., 2004). There is no significant interaction between statin administered in combination either with niacin or fibrate.

Therefore, the present study was designed to evaluate and compare the effects and safety of combination therapy of statin-niacin and statin-fenofibrate on dyslipidemic patients of high-risk group. The result of study would suggest for rational use of lipid lowering agents and thereby reduce morbidity and mortality of cardiovascular disease.

\section{Materials and Methods}

This prospective interventional study was carried out during the period of July 2006 to June 2007. The patients admitted in coronary care unit with diagnosis of a coronary heart disease and dyslipidemia were taken as study population. Adult male and female patients of 3065 years of age having coronary heart disease with dyslipidemia (LDL-C level was detected more than 100 $\mathrm{mg} / \mathrm{dL}$, triglyceride more than $200 \mathrm{mg} / \mathrm{dL}$, total 
cholesterol more than $200 \mathrm{mg} / \mathrm{dL}$ and HDL-C level less than $40 \mathrm{mg} / \mathrm{dL}$ in male, $50 \mathrm{mg} / \mathrm{dL}$ in female), defined as high-risk category by updated NCEP ATP-III Guidelines 2004 were included in this study (Grundy et al., 2004). Exclusion criteria were chronic hepatic disorder, renal impairment, pregnant and lactating mothers, on going treatment with other drugs that affect lipids ( $B-$ blocker, steroid therapy, etc.), extreme level of triglyceride $(>400 \mathrm{mg} / \mathrm{dL})$, hypersensitivity to any component of this medication, those who did not give informed consent and on going treatment with lipid lowering agents.

After selection of the participants, written consent was obtained after explanation of the objectives, nature, purpose and potential risk of all procedures used for the study to the patient and accompanying persons. Detail history (particulars of the patient, personal history, family history of coronary heart disease and associated disease like hypertension, diabetes) and clinical examination (pulse, blood pressure, jaundice, height and weight, etc.) were taken in a prescribed data collection form. Blood samples were collected from the study subjects after 12 hours overnight fasting for estimation of serum level of glucose, triglyceride, total cholesterol, HDL-C, LDL-C, SGPT and serum creatinine.

Initially there were 132 study populations, among them 24 were excluded. 108 patients satisfied the inclusion, exclusion criteria and they were allocated to Group I (64 patients) and Group II (44 patients). Group I was treated with niacin $1 \mathrm{~g}$ (500 $\mathrm{mg}$ twice daily) plus atorvastatin $10 \mathrm{mg}$ daily for 12 weeks and Group II was treated with fenofibrate $200 \mathrm{mg}$ plus atorvastatin $10 \mathrm{mg}$ daily for 12 weeks. Among Group I, 26 patients did not turn to follow-up (dropped out), 3 died while 35 patients completed the study. Of them 28 were males and 7 were females. In Group II, 11 patients did not turn to follow-up, 1 died and 32 patients completed the study. Of them 30 were males and 2 were females. A total number of 67 patients completed the study.

Average duration of hospital stay of the patients was 5 to 7 days. All patients of both groups were instructed to maintain TLC such as low fat diet during the trial period. During discharge from hospital all the study participants were instructed about possible adverse effects and to report to the principal investigator if they experience any sort of drug related adverse events such as warming of the face, neck and shoulder; intense muscle pain, headache, yellow coloration of skin and eye, etc. within this period either over telephone or physically.

All the participants were advised to report to the cardiology outpatient department following overnight fasting, 12 weeks after initiation of lipid lowering drug. On that day along with clinical examination blood samples were collected and relevant test was done and test results were also recorded.

From each study subject $5 \mathrm{~mL}$ fasting venous blood sample was collected by disposable plastic syringe with all aseptic precautions. The needle was detached from the nozzle and blood was transferred immediately into a dry, clean and plain plastic test tube without any anticoagulant with a gentle push to avoid hemolysis. Serum was separated by centrifugation at the rate of 3,000 rpm for $15 \mathrm{~min}$. Estimations were carried out as early as possible. Whenever there was delay, sample was stored at $-20^{\circ} \mathrm{C}$.

Data were collected through preformed data collection sheet by pre-tested questionnaire, clinical examination, ECG and biochemical examinations. After an overnight fasting, total cholesterol and HDL-C were measured by CHOD-PAP method using reagents of Biocon ${ }^{\circledR}$ Germany by spectrophotometer. Triglycerides were also measured by GPO-PAP method using reagents of Biocon ${ }^{\circledR}$ Germany by spectrophotometer (Gowland, 1998). LDL cholesterol was calculated by Friedewald formula (in mg/dL) [LDL-C = TC- (TG/5 + HDL-C)]. Estimation of serum glucose was done by GOD-PAP method (McLauchlan, 1998). Estimation of SGPT was performed by colorimetric method (Handerson and Donald, 2001). For estimation of serum creatinine kinetic method was used (David and Chistopher, 2001).

All statistical analyses were done by SPSS software package, 12.0 for windows. Values were presented as mean \pm SD. $95 \%$ significance level $(\mathrm{p}<0.05)$ was considered statistically significant. Paired t-test was done to compare between means within groups and ' $\mathrm{Z}$ ' proportion test was done to see any significant difference between the study parameters.

The study was approved by Ethics Review Committee of Sylhet M.A.G. Osmani Medical College. Informed written consent was taken from all participants prior to study.

\section{Results}

Mean ages for Group I and II were $50.7 \pm 10.0$ years and 
Table I

Effects of niacin or fenofibrate in combination with atorvastatin on serum lipid level

\begin{tabular}{|lcccccc|}
\hline \multirow{2}{*}{$\begin{array}{l}\text { Lipid profile } \\
(\mathrm{mg} / \mathrm{dL})\end{array}$} & \multicolumn{2}{c}{ Niacin plus atorvastatin } & \%Change & \multicolumn{2}{c|}{ Fenofibrate plus atorvastatin } & \%Change \\
\cline { 2 - 8 } & Before treatment & $\begin{array}{c}12 \text { weeks after } \\
\text { treatment }\end{array}$ & & Before treatment & $\begin{array}{c}12 \text { weeks after } \\
\text { treatment }\end{array}$ \\
Triglyceride & $207.8 \pm 60.2$ & $178.6 \pm 52.8^{\mathrm{a}}$ & -14.0 & $289.7 \pm 86.6$ & $188.2 \pm 49.3^{\mathrm{a}}$ & -35.0 \\
$\begin{array}{l}\text { Total choles- } \\
\text { terol }\end{array}$ & $213.5 \pm 28.5$ & $158.6 \pm 19.5^{\mathrm{a}}$ & -25.7 & $224.6 \pm 26.1$ & $156.7 \pm 24.8^{\mathrm{a}}$ & -30.2 \\
LDL-C & $136.8 \pm 23.6$ & $84.2 \pm 15.4^{\mathrm{a}}$ & -38.4 & $134.5 \pm 28.6$ & $82.6 \pm 20.1^{\mathrm{a}}$ & -38.6 \\
HDL-C & $35.3 \pm 3.6$ & $38.8 \pm 3.8^{\mathrm{a}}$ & +10.0 & $35.0 \pm 4.0$ & $37.6 \pm 3.5^{\mathrm{a}}$ & +7.2 \\
\hline
\end{tabular}

aSignificance of difference at $\mathrm{p}<0.001$; '-' sign indicates reduction of lipid level in percentage; ' + ' sign indicates increase of lipid level in percentage; Data are mean $\pm S D$

$47.6 \pm 8.3$ years respectively. There was no significant difference between Group I and II in their age distribution. Of the study subjects $25(71.4 \%)$ of Group I and $27(84.4 \%)$ of Group II were smokers. Family history of coronary heart disease were found in $23(65.7 \%)$ and 20 $(62.5 \%)$ patients of Group I and II respectively. Obesity (BMI>25 kg/m²) was detected $12(34.3 \%)$ in Group I and Group $11(34.4 \%)$ in II. History of sedentary life style was $10(28.6 \%)$ in Group I and 8 (25.6\%) in Group II. Around $34 \%$ of the study subjects were diabetic in both groups, while $42.9 \%$ of Group I and $62.5 \%$ of Group II were hypertensive. All patients of both groups were match in respect to age, risk factors (history of smoking, family history of coronary heart disease, obesity, sedentary life style) and associated diseases (diabetes, hypertension).

Before administration of niacin-atorvastatin combination, fasting serum lipid profile was measured (Table I). Serum levels of triglyceride, total cholesterol, LDL-C, HDL-C levels were $207.8 \pm 60.2 \mathrm{mg} / \mathrm{dL}, 213.5 \pm 28.5$ $\mathrm{mg} / \mathrm{dL}, 136.8 \pm 23.6 \mathrm{mg} / \mathrm{dL}$ and $35.3 \pm 3.6 \mathrm{mg} / \mathrm{dL}$ respectively. After 12 weeks of treatment, triglyceride level was reduced from $207.8 \pm 60.2 \mathrm{mg} / \mathrm{dL}$ to $178.6 \pm$ $52.8 \mathrm{mg} / \mathrm{dL}$. This change was statistically significant $(\mathrm{t}=4.677, \mathrm{p}<0.001,95 \%$ CI 16.47 to 41.80$)$. Triglyceride decreased by $14.03 \%$.

Total cholesterol level was reduced from $213.5 \pm 28.5$ $\mathrm{mg} / \mathrm{dL}$ to $158.6 \pm 19.5 \mathrm{mg} / \mathrm{dL}$ and this change was statistically significant $(\mathrm{t}=14.706, \mathrm{p}<0.001,95 \%$ CI 47.350 to 62.535$)$. Reduction of total cholesterol was $25.7 \%$ from the baseline level.

LDL-C level was observed to decrease from $136.8 \pm 23.6$ $\mathrm{mg} / \mathrm{dL}$ to $84.2 \pm 15.4 \mathrm{mg} / \mathrm{dL}$ and this reduction was statistically significant $(\mathrm{t}=15.448, \mathrm{p}<0.001,95 \%$ CI 45.631 to 59.455). Percentage change of LDL-C was $38.4 \%$ decrease from baseline.
HDL-C level increased from $35.3 \pm 3.6 \mathrm{mg} / \mathrm{dL}$ to $38.8 \pm$ $3.8 \mathrm{mg} / \mathrm{dL}$ which was statistically significant $(\mathrm{t}=7.218$, $\mathrm{p}<0.001,95 \%$ CI 4.540 to 2.545$)$. Niacin-atorvastatin treated group demonstrated increase in HDL-C level by $10.0 \%$ from pre-treatment level.

Before initiation of treatment of fenofibrate-atorvastatin combination fasting serum level of triglyceride, total cholesterol, LDL-C and HDL-C were $289.7 \pm 86.6 \mathrm{mg} /$ $\mathrm{dL}, 224.6 \pm 26.1 \mathrm{mg} / \mathrm{dL}, 134.5 \pm 28.6 \mathrm{mg} / \mathrm{dL}$ and $35.0 \pm$ $4.0 \mathrm{mg} / \mathrm{dL}$ respectively. After completion of 12 weeks of treatment, triglyceride level was decreased from $289.7 \pm 86.6 \mathrm{mg} / \mathrm{dL}$ to $188.2 \pm 49.3 \mathrm{mg} / \mathrm{dL}$. This change was statistically highly significant $(t=6.854, p<0.001$, $95 \%$ CI 71.276 to 131.661$)$. Triglyceride decreased by $35.0 \%$.

Total cholesterol level was reduced from $224.6 \pm 26.1$ $\mathrm{mg} / \mathrm{dL}$ to $156.7 \pm 24.8 \mathrm{mg} / \mathrm{dL}$ and this changes was statistically significant $(t=14.366, p<0.001 ; 95 \%$ CI 58.239 to 77.511$)$. Percentage decrease of total cholesterol was $30.2 \%$.

LDL-C level reduced from $134.5 \pm 28.6 \mathrm{mg} / \mathrm{dL}$ to $82.6 \pm$ $20.1 \mathrm{mg} / \mathrm{dL}$ and the reduction was statistically highly significant ( $\mathrm{t}=12.501, \mathrm{p}<0.001 ; 95 \% \mathrm{CI} 43.438$ to 60.375 ). Percentage change of LDL-C by $38.6 \%$ from baseline was observed.

HDL-C level was observed to be increased from $35.0 \pm$ $4.0 \mathrm{mg} / \mathrm{dL}$ to $37.6 \pm 3.5 \mathrm{mg} / \mathrm{dL}$. These changes of increment was statistically significant $(\mathrm{t}=4.079, \mathrm{p}<0.001$, $95 \%$ CI 3.797 to 1.266). Fenofibrate-atorvastatin combina -tion caused increase of HDL-C by $7.2 \%$.

Z-proportion test was done to see the difference in percentage change of lipid profile between two treatment groups after 12 weeks of administration. In fenofibrate-atorvastatin treatment group more effective reduction of triglyceride level noted, compared to 
Table II

\begin{tabular}{|c|c|c|c|c|}
\hline \multirow[b]{2}{*}{$\begin{array}{l}\text { Biochemical } \\
\text { parameters }\end{array}$} & \multicolumn{2}{|c|}{ Niacin plus atorvastatin } & \multicolumn{2}{|c|}{ Fenofibrate plus atorvastatin } \\
\hline & $\begin{array}{l}\text { Before administration } \\
\qquad(\mathrm{n}=35)\end{array}$ & $\begin{array}{l}\text { After } 12 \text { weeks } \\
\quad(\mathrm{n}=35)\end{array}$ & $\begin{array}{l}\text { Before administration } \\
\qquad(\mathrm{n}=35)\end{array}$ & $\begin{array}{l}\text { After } 12 \text { weeks } \\
\quad(\mathrm{n}=35)\end{array}$ \\
\hline $\begin{array}{l}\text { Fasting blood glucose } \\
(\mathrm{mmol} / \mathrm{L})\end{array}$ & $7.2 \pm 2.7$ & $6.6 \pm 1.3^{\mathrm{NS}}$ & $8.5 \pm 4.4$ & $6.5 \pm 2.0^{\mathrm{a}}$ \\
\hline SGPT (U/L) & $36.8 \pm 16.4$ & $35.3 \pm 10.1^{\mathrm{NS}}$ & $30.2 \pm 7.8$ & $45.6 \pm 24.8^{a}$ \\
\hline $\begin{array}{l}\text { Serum creatinine } \\
(\mathrm{mg} / \mathrm{dL})\end{array}$ & $1.2 \pm 0.3$ & $1.0 \pm 0.2^{\mathrm{a}}$ & $1.1 \pm 0.3$ & $1.0 \pm 0.1^{\mathrm{NS}}$ \\
\hline
\end{tabular}

aSignificant difference before and after 12 weeks administration of drug at $p<0.001 ;$ NS $=$ No significant difference at $p>0.05$, Data are mean \pm SD

\begin{tabular}{|c|c|c|}
\hline \multicolumn{3}{|c|}{ Table III } \\
\hline \multicolumn{3}{|c|}{ Adverse drug reactions in course of treatment } \\
\hline Symptoms & $\begin{array}{c}\text { Niacin plus } \\
\text { atorva- statin }(\mathrm{n}= \\
35)\end{array}$ & $\begin{array}{l}\text { Fenofibrate plus } \\
\text { atorvastatin }(\mathrm{n}= \\
32)\end{array}$ \\
\hline Flushing & 5 & -- \\
\hline Headache & 2 & 1 \\
\hline Fatigue & 4 & 4 \\
\hline $\begin{array}{l}\text { Abdominal } \\
\text { pain }\end{array}$ & 2 & 2 \\
\hline Dyspepsia & -- & 2 \\
\hline Myalgia & -- & 2 \\
\hline Total & 13 & 11 \\
\hline
\end{tabular}

niacin-atorvastatin combination therapy $(Z=2.05$, $\mathrm{p}<0.05)$. But there was no differences in total cholesterol, LDL-C and HDL-C modifying effects between these two combination treatment groups.

Before initiation of niacin-atorvastatin combination, fasting blood glucose level was $7.2 \pm 2.7 \mathrm{mmol} / \mathrm{L}$ (Table II). After 12 weeks of treatment, fasting blood glucose was detected as $6.6 \pm 1.3 \mathrm{mmol} / \mathrm{L}$. There was no significant change in fasting blood glucose $(t=1.71, p>0.05$; 95\% CI 0.111 to 1.30 ) level.

Before administration of niacin plus atorvastatin, mean SGPT was $36.8 \pm 16.4 \mathrm{U} / \mathrm{L}$. After 12 weeks of treatment SGPT was detected as $35.3 \pm 10.1 \mathrm{U} / \mathrm{L}$. There was no significant difference of SGPT level $(t=0.561, p>0.05$; $95 \%$ CI -4.048 to 7.134$)$.

Before initiation of Group I treatment serum creatinine level was $1.2 \pm 0.3 \mathrm{mg} / \mathrm{dL}$ and after completion of 12 weeks of treatment, serum creatinine level was $1.0 \pm 0.2$ $\mathrm{mg} / \mathrm{dL}$. Serum creatinine level significantly decreased from pre-treatment level $(\mathrm{t}=3.56, \mathrm{p}<0.001 ; 95 \%$ CI 0.073 to 0.269$)$. But the change was not associated with renal impairment.

In Group II before initiation of treatment, fasting blood glucose was $8.5 \pm 4.4 \mathrm{mmol} / \mathrm{L}$. After completion of 12 weeks of treatment fasting blood glucose was $6.5 \pm 2.0$ $\mathrm{mmol} / \mathrm{L}$. The fasting blood glucose decreased significantly ( $\mathrm{t}=3.82$, $\mathrm{p}<0.001 ; 95 \%$ CI 0.946 to 3.116 ) but the change was within normal limit.

Before administration of fenofibrate-atorvastatin combination, SGPT was $30.2 \pm 7.8 \mathrm{U} / \mathrm{L}$. After 12 weeks of treatment, SGPT was detected as $45.6 \pm 24.8 \mathrm{U} / \mathrm{L}(\mathrm{t}=-$ $3.67, \mathrm{p}<0.001 ; 95 \% \mathrm{CI}-23.96$ to -6.85$)$. SGPT in this group increased significantly.

Before initiation of treatment, serum creatinine was 1.1 $\pm 0.3 \mathrm{mg} / \mathrm{dL}$. After 12 weeks of treatment, serum creatinine level was detected as $1.0 \pm 0.1 \mathrm{mg} / \mathrm{dL}$. The changes in serum creatinine level was not significant $(\mathrm{t}=1.69, \mathrm{p}>0.05$; $95 \%$ CI -0.019 to 0.201$)$.

Treatment related adverse effect was reported in 37.1\% of patients receiving niacin plus atorvastatin therapy and in $35 \%$ of patients receiving another combination of fenofibrate plus atorvastatin (Table III). 14.3\% of Group I treated patients experienced transient flushing which was a feeling of warmth, itching and redness of the skin especially face as well as neck while none of them complaints in Group II. 5.7\% of niacin plus atorvastatintreated patients and $3.6 \%$ of fenofibrate plus atorvastatin-treated patients experienced headache. $11.4 \%$ of Group I treated patients and $12.5 \%$ of Group II treated patient's had complained of fatigue. Abdominal pain experienced by $5.7 \%$ in Group I and $6.3 \%$ in Group II. $6.3 \%$ of fenofibrate plus atorvastatin treated patient's complaints of dyspepsia and myalgia while none of the niacin plus atorvastatin treated patients, experienced dyspepsia or myalgia. 


\section{Discussion}

This study shows that combined therapy of either niacin-atorvastatin or fenofibrate-atorvastatin for 12 weeks significantly decreased total cholesterol, triglyceride and LDL-C from baseline in dyslipidemic patients. The individual combination also significantly increased HDL-C in same groups of patients. This study also revealed that combined fenofibrate-atorvastatin appeared more effective than niacin-atorvastatin in reduction of triglyceride. Previously, similar combinations of lipid lowering agents produced qualitatively similar effects in dyslipidemic patients (Stein et al., 1996; Guyton et al., 1998; Athyros et al., 2002; Klosiewicz-Latoszek et al., 2004). However, a study conducted by Deb (2006) where atorvastatin administered in combination with ezetimibe produced significant reduction of LDL-C and total cholesterol, but did not show any significant effect on HDL-C and triglyceride level compared to baseline.

In the present study, niacin administered in combination with atorvastatin significantly decreased triglyceride by $14.0 \%$, total cholesterol by $25.7 \%$ and LDL-C by $38.4 \%$ and increased HDL-C by $10.0 \%$ from baseline. This result was similar to that reported by Stein et al., (1996) who observed that niacin at a dose of $1.5 \mathrm{~g}$ administered in combination with simvastatin at a dose of $10 \mathrm{mg}$ per day was highly effective in lowering the serum lipids of triglyceride by $31 \%$, LDL-C by $29 \%$ while HDL-C level increased by $31 \%$ after 17 weeks of treatment. The greater lipid modifying effects might be due to high doses of niacin and long duration of treatment.

Guyton et al., showed that $1.5 \mathrm{~g}$ niacin in combination with $10 \mathrm{mg}$ simvastatin lowered level of total cholesterol by $23 \%$, LDL-C by $32 \%$, triglyceride by $30 \%$ and increased levels of HDL-C by $26 \%$ after 48 weeks of therapy. The difference of percentage of lipid profile was probably due to longer duration and higher dose of niacin.

Niacin mainly acts by inhibition of lipolysis of triacylglycerol in adipose tissue via inhibition of hormone sensitive triglyceride lipase leading to reduction in circulating levels of non-esterified fatty acid. As a result, there is a reduction in plasma level of VLDLtriglyceride, LDL and decreases the rate of removal of apoA-1 (the major apolipoprotein of HDL) by the liver (Chapman et al., 2004). There is also evidence that nicotinic acid stimulates cholesterol efflux via an ATPbinding cassette transporter A1 (ABCA-1) mediated mechanism (Rubic et al., 2004) and decrease HDL uptake by the liver (Sakai et al., 2001) which contribute to the HDL raising effect. Atorvastatin inhibits HMGCoA reductase, the most effective agent for lowering LDL-C (Miller, 2003).

On the other hand, the present study shows that fenofibrate plus atorvastatin therapy decreased LDL by $38.6 \%$, total cholesterol by $30.2 \%$, triglyceride by $35.0 \%$ and increased HDL-C by $7.2 \%$ from the baseline. The changes might be caused by fenofibrate that activates peroxisome proliferator-activator receptors (Staels and Auwerx, 1998) which induce an increase in lipoprotein lipase activity causing hydrolysis of triglycerides in chylomicron and VLDL particles and an increase in apo A-1 as well as a reduction in cholesterol ester transfer protein activity; thereby reduction of triglyceride, total cholesterol and increase HDL-C. Atorvastatin decreases LDL-C by inhibition of HMG-CoA reductase (Watts and Dimmit, 1999).

The study of Athyros et al. (2002) showed that combination therapy of atorvastatin (20 mg)-fenofibrate (200 $\mathrm{mg}$ ) causes reduction of total cholesterol, LDL-C, triglyceride and a significant increase in HDL-C which was highly beneficial in patients with type 2 diabetes and dyslipidemia. The differences of lipid profile probably due to higher doses of atorvastatin and longer duration of treatment which was twice that of the present study.

Another study conducted by Klosiewicz-Latoszek et al. (2004) on fenofibrate (200 $\mathrm{mg}$ ) administered with simvastatin $(20 \mathrm{mg})$ therapy observed reduction of total cholesterol, triglyceride and LDL-C and increased HDL -C from baseline level. This study apparently consistent with the present study where simvastatin $(20 \mathrm{mg})$ used in place of atorvastatin $(10 \mathrm{mg})$ and duration of treatment was 12 months.

According to NCEP ATP-III and most recent guidelines of European Society of Cardiology recommended that reduction of LDL-C by statin and simultaneously elevation of HDL-C by niacin or fibrate contributes to prevention of cardiovascular disease and atheromatous lesions, consequently decrease morbidity and mortality (Grundy et al., 2004; Sirtori, 2006). Regarding these two parameters niacin-atorvastatin has similar effect in relation to fenofibrate-atorvastatin combination.

A study conducted by Barter and Rye (2006) showed that an $8 \%$ increase in HDL-C predicted a coronary heart disease risk reduction of $23 \%$ whereas a $7 \%$ reduction in LDL-C predicted a $15 \%$ reduction in 
coronary heart disease events. Another study reported by Gordon et al. (1977) suggests that a one percent increment in HDL-C equated with a $1 \%$ lowering of cardiovascular risk.

In our study niacin-atorvastatin treated subjects exhibit some adverse effects such as, transient flushing, headache, fatigue and abdominal pain. In addition, this group did not experience either myalgia or dyspepsia. In the study conducted by Millers, (2003), the incidence of flushing was $10 \%$, which was almost similar to the present observation and mediated by $\mathrm{PGD}_{2}$. Millers, (2003) also reported that there was no complaints of myopathy and $0.5 \%$ of patients had increased aminotransferase level three times more than the upper limit of normal. The present study differs from Miller, (2003) where there was neither significant increment of aminotransferase nor any sorts of clinical events.

Fenofibrate in combination with atorvastatin treated group complaints of headache, fatigue, abdominal pain, dyspepsia and myalgia. However, flushing was not observed in this study group. Davidson, (2003) observed that long duration of treatment by fenofibrate with high dose of statin combination causes myopathy and rhabdomyolysis.

There was a significant difference of serum creatinine level after 12 weeks of treatment with niacin-atorvastatin while no significant difference was observed in fenofibrate-atorvastatin. However, this change was within normal limit.

After 12 weeks of treatment neither of the treated group shows any significant increment of plasma glucose level. This study also analyzed serum alanine aminotransferase to assess liver function test in both Groups. Persistent elevation of ALT, three times higher than the upper limit of normal is considered clinically important (Illingworth et al., 2001). The present study showed that after completion of niacin-atorvastatin treatment, there was no significant difference in SGPT level. But SGPT level was significantly increased in fenofibrate-atorvastatin treated group. Adverse effect did not require withdrawal of drugs in any group. But significantly raised SGPT level in fenofibrate-atorvastatin combination implies that monitoring of liver function should be done to assess hepatic impairment with this regimen.

This study suggests that both combinations are equally effective in dyslipidemia. Although, fenofibrateatorvastatin combination decreased more triglyceride level and niacin-atorvastatin combination appeared safer considering some adverse effects.

\section{Conclusion}

This study was conducted on a small number of patients, in a single center and follow-up was limited for 12 weeks only. As the trial duration was short, analysis of long-term effects and safety was not possible. Other limitations were lack of randomization and matching of sex in female as a risk factor. Assessment of creatinine phosphokinase level for evaluation of muscle related adverse events was not done in this study. This study needs further extensive investigation with randomized double blind, multicentre trials with different dose schedule and different combination for better assessment of long-term effects and safety profile.

\section{References}

Athyros VG, Papageorgiou AA, Athyrou VV, Demitriadis DS, Kontopoulos AG. Atorvastatin and micronized fenofibrate alone and in combination in type 2 diabetes with combined hyperlipidemia. Diabetic Care 2002; 25: 1198-1202. http:// dx.doi.org/10.2337/diacare.25.7.1198

Barter PJ, Rye KA. Cardioprotective properties of fibrates; Which fibrate, which patients, what mechanism? Circulation 2006; 113: 1553-55. http://dx.doi.org/10.1161/ CIRCULATIONAHA.105.620450

Bovet P, Shamlaye C, Gabriel A, Riesen W, Paccaud F. Prevalence of cardiovascular risk factors in a middle-income country and estimated cost of a treatment strategy. BMC Public Health 2006; 6: 9. http://dx.doi.org/10.1186/14712458-6-9

Bruckert E. Epidemiology of low HDL-cholesterol: Results of studies and surveys. Eur Heart J Suppl. 2006; 8F: 17-22. http:/ / dx.doi.org/10.1093/eurheartj/sul036

Chapman MJ, Assmann G, Fruchart JC. Raising high-density cholesterol with reduction of cardiovascular risk: The role of nicotinic acid- A position paper development by the European Consensus Panel on HDL-C. Curr Med Res Opin. $2004 ; \quad 20: \quad 1253-68$. h t t p : / / dx.doi.org/10.1185/030079904125004402

Chockalingam A, Campbell N. Management of hypertension: Diagnosis and lifestyle modification. Indian Heart J. 2005; 57: 639-43.

Davidson M. Statin, fibrate combination therapy: What is the real story? Cardiology Express Report. USA, MMC, Inc., 
2003, pp 1-4.

David JN, Chistopher PP. Renal function and nitrogen metabolites. In: Tietz textbook of clinical chemistry. 5th ed. Burtis CA, Ashwood ER (eds). India, Harcourt Brace and Company Asia Ltd, 2001, pp 1241-45.

Deb MR. A comparative study on the effects of atorvastatin administered alone and in combination with ezetimibe in the management of dyslipidemia. MPhil Thesis, Shahjalal University of Science \& Technology, Bangladesh, 2006.

Deedwania P, Singh V. Coronary artery disease in South Asians: Evolving strategies for treatment and Prevention. Indian Heart J. 2005; 57: 617-31.

Derosa G, Cicero AE, Bertone G. Comparision of fluvastatin plus fenofibrate combination therapy and fluvastatin monotherapy in the treatment of combined hyperlipidaemia, type 2 diabetes mellitus, and coronary heart disease: A 12month randomized, double-blind, controlled trial. Clin Ther. 2004; 26: 1599-1607. http://dx.doi.org/10.1016/ j.clinthera.2004.10.008

Eckardstein AV. Introduction: New thinking for managing dyslipidemia. Curr Med Res Opin. 2005; 21 S: 1-2.

Fodor JG, Frohlich JJ, Genest JJG Jr, McPherson PR. Recommendations for the management and treatment of dyslipidemia. CMAJ. 2000; 162: 1441-47.

Gordon T, Castalli WP, Hjortland MC, Kannel WB, Dawber TR. High density lipoprotein as a protective factor against coronary heart disease: The Framingham study. Am J Med. 1977; 62: 707-14. http://dx.doi.org/10.1016/0002-9343(77) 90874-9

Gowland E. Lipid and lipoprotein. In: Varley's Practical clinical biochemistry. 6th ed. Gowenlock AH (ed). London, Butterworth Heinemann, 1998, pp 452-76.

Grundy SM, Cleeman JI, Merz CNB, Brewer HB JR, Clark LT, Hunninghake DB, et al. Implications of recent clinical trials for the National Cholesterol Education Program Adult Panel III Guidelines. Circulation 2004; 110: 227-39. h t t p : / / dx.doi.org/10.1161/01.CIR.0000133317.49796.0E

Guyton JR, Goldberg AC, Kreisberg RA, Sprecher DL, Superko HR, O'Connor CM. Effectiveness of once-nightly dosing of extended-release niacin alone and in combination for hypercholesterolemia. Am J Cardiol. 1998; 82: 737-43. http:// dx.doi.org/10.1016/S0002-9149(98)00448-2

Handerson AR, Donald WM. Enzymes. In: Tietz textbook of clinical chemistry. 5th ed. Burtis CA, Ashwood ER (eds). India, Harcourt Brace and Company Asia Ltd, 2001, pp 35289.

Illingworth DR, Crouse JR, Hunninghake DB, Davidson $\mathrm{MH}$, Escobar ID, Stalenhoef AFH, et al. A comparison of simvastatin and atorvastatin up to maximal recommended doses in a large multicenter randomized clinical trial. Curr
Med Res Opin. 2001; 17: 43-50. http:// dx.doi.org/10.1185/03007990152005351

Klosiewicz-Latoszek L, Szostak WB, Grzybowska B, Bialobrzeska-Paluszkiewicz J, Wisniewska B, et al. Comparision of combined statin-fibrate treatment to monotherapy in patients with mixed hyperlipidemia. Kardiol Pol. 2004; 60: 567-77.

Koh KK, Michael J, Han SH, Chung WJ, Ahn JY, Seo YH, et al. Additive beneficial effects of fenofibrate combined with atorvastatin in the treatment of combined hyperlipidemia. J Am Coll Cardiol. 2005; 45: 1649-53. http:// dx.doi.org/10.1016/j.jacc.2005.02.052

McKeigue PM, Miller GJ, Marmot MG. Coronary heart disease in south Asians overseas: A review. J Clin Epidemiol. 1989; 42: 597-609. http://dx.doi.org/10.1016/0895-4356(89)90002-4

McLauchlam DM. Glucose, other sugars and ketone. In: Varley' Practical clinical biochemistry. 6th ed. Gowenlock AH (ed). London, Butterworth Heinemann, 1998; pp 320-32.

Miller M. Niacin as a component of combination therapy for dyslipidemia. Mayo Clinic Proceedings. 2003; 78: 735-42.

Misra A, Vikram NK, Arya S, Pandey RM, Dhingra V. High prevalence of insulin resistance in post-pubertal Asian Indian children is associated with adverse truncal body fat patterning, abdominal adiposity and excess body fat. Int J Obes Relat Metab Disord. 2004; 28: 1217-26. http:// dx.doi.org/10.1038/sj.ijo.0802704

Patel JV, Kirby M, Hughes EA. The lipid adults: Analysis of lipid management in two centres in Britain 2003. Br J Cardiol. 2004; 11: 214-17.

Rubins HB, Robins SJ, Collins D, Iranmanesh A, Wilt TJ, Rutan $\mathrm{GH}$, et al. Distributions of lipids in 8,500 men with coronary artery disease. Department of Veterans Affairs HDL' Intervention Trial Study Group. Am J Cardiol. 1995; 75: 11961201.

Rubic T, Trottmann M, Lorenz RL. Stimulation of CD36 and the key effector of reverse cholesterol transport ATP-binding cassette A1 in monocytoid cells by niacin. Biochem Pharmacol. 2004; 67: 411. http://dx.doi.org/10.1016/ j.bcp.2003.09.014

Sakai T, Kamanna VS, Kashyap ML. Niacin, but not gemfibrozil, selectively increases LP-AI, a cardioprotective subfraction of HDL, in patients with low HDL cholesterol. Arterioscler Thromb Vasc Biol. 2001; 21: 73-79.

Sirtori CR. HDL and the progression of atherosclerosis: New insights. Eur Heart J Suppl. 2006, 8 F: 4-9.

Staels B, Auwerx J. Regulation of apoA-1gene expression by fibrates. Atherosclerosis 1998; 137: 19-23. http:// dx.doi.org/10.1016/S0021-9150(97)00313-4

Stein EA, Davidson MH, Dujovne CA. Efficacy and tolerability of low-dose simvastatin and niacin, alone and in combination, in patients with combined hyperlipidemia: A 
prospective trial. J Cardiovasc Pharmacol. 1996; 1: 107-16.

Sultana N, Haque MN, Ali MS, Begum BA, Jahan N, Akter S, et al. A comparative study of body iron status and lipid profile in acute myocardial infarction patients. Mymensingh Med J. 2002; 11: 87-90.

Taylor AJ. Evidence to support aggressive management of HDL-cholesterol: Implications of recent trials. Eur Heart J Suppl. 2006, 8 F: 74-80.
Venkataraman R, Nanda NC, Baweja G, Parikh N, Bhatia V. Prevalence of diabetes mellitus and related conditions in Asian Indians living in the United States. Am J Cardiol. 2004; 94: 977-80. http://dx.doi.org/10.1016/j.amjcard.2004.06.048

Watts GF, Dimmitt SB. Fibrate dyslipoproteinemia and cardiovascular disease. Curr Opin Lipid 1999; 10: 561-74.http:// dx.doi.org/10.1097/00041433-199912000-00011 